http://www.jdms.dentaiau.ac.ir
JRDMS Journal of Research in Dental and Maxillofacial Sciences
$\mathrm{p}(\mathrm{ISSN}): 2588-4166$

\title{
A Noninvasive Approach for Management of Recurrent Oral Mucocele in Pediatric Patients: A Therapeutic Case Report
}

\author{
N Gholami ${ }^{1}$, S Badakhsh ${ }^{2}$ \\ ${ }^{1}$ Assistant Professor, Department of Oral and Maxillofacial Medicine, Tehran University of Medical Sciences, Tehran-Iran. \\ ${ }^{2}$ Assistant Professor, Department of Pediatric Dentistry, Tehran University of Medical Sciences, Tehran- Iran.
}

\begin{tabular}{|c|c|}
\hline ARTICLE INFO & ABSTRACT \\
\hline $\begin{array}{l}\text { Article Type } \\
\text { Case Report }\end{array}$ & Background:Mucocele is a clinical term referring to a swelling caused by saliva \\
\hline $\begin{array}{l}\text { Article History } \\
\text { Received: May } 2018 \\
\text { Accepted: Apr } 2018 \\
\text { ePublished: Jun } 2018\end{array}$ & $\begin{array}{l}\text { duct. This article reports the efficiency of intralesional corticosteroid injection in } \\
\text { the treatment of a recurrent oral mucocele in a pediatric patient. } \\
\text { Case presentation: A 7-year-old girl presented with the chief complaint of a pain- } \\
\text { less swelling on the lower lip. A gradual increase in size with some episodes of }\end{array}$ \\
\hline $\begin{array}{l}\text { Keywords: } \\
\text { Mucocele, } \\
\text { Pediatric Dentistry, } \\
\text { Triamcinolone Acetonide, } \\
\text { Injections }\end{array}$ & $\begin{array}{l}\text { emptying was noticed. The intraoral examination revealed a sessile, nodular and } \\
\text { exophytic lesion on the lower lip. Two consecutive intralesional injections of } 40 \\
\text { mg/ml triamcinolone acetonide were done at the base of the lesion. A significant } \\
\text { reduction in size was observed after the first injection, and the lesion disappeared } \\
\text { after two weeks. No recurrence was noticed during the one-year follow-up. } \\
\text { Conclusion: Intralesional corticosteroid injection may be considered a less inva- } \\
\text { sive and cost-effective approach for the management of oral mucoceles. }\end{array}$ \\
\hline
\end{tabular}

DOI: $10.29252 / j r d m s .3 .3 .49$

Please cite this paper as: Gholami N, Badakhsh S. A noninvasive approach for management of recurrent oral mucocele in pediatric patients: a therapeutic case report. J Res Dent maxillofac Sci. 2018; 3(3):49-52. 


\section{Introduction:}

Mucocele is a clinical term which refers to "a swelling caused by the accumulation of saliva at the site of an obstructed or traumatized minor salivary gland duct". ${ }^{(1)}$ There are two types of mucocele including the extravasation and retention types. The former type is more common and is believed to be the result of trauma to the main duct of salivary glands, which leads to the formation of a pseudocyst. ${ }^{(1,2)}$

Mucocele most commonly develops on the lower lip followed by the floor of the mouth and buccal mucosa. ${ }^{(3)}$ No gender tendency has ever been reported, and the lesion predominantly affects the individuals in their second decade of life. ${ }^{(3)}$ Superficial lesions manifest as vesicles, whereas deep lesions have a nodular appearance. Fibrosis may occur in a long-standing mucocele. (2) Mucoceles regularly present as distinct, painless swellings with smooth surfaces, ranging in diameter from a few millimeters to a few centimeters. $^{(1)}$

Although they usually disappear due to spontaneous rupture, frequent recurrences may occur, which need therapeutic intervention..$^{(2)}$ Although surgery is considered as a conventional primary treatment approach, other suggested alternatives include laser-irradiation, cryosurgery, micromarsupialization, and steroid injection. ${ }^{(4-6)}$.

In pediatric patients, noninvasive treatments result in more effective behavior management. Here, we present a less invasive management of a large recurrent mucocele on the lower lip of a 7-year-old girl.

\section{Case Presentation}

A 7-year-old girl was referred to the pediatric dentistry department of Zanjan University of Medical Sciences, Zanjan, Iran, with the chief complaint of a swelling on the lower lip, which appeared about a year ago (Figure 1).

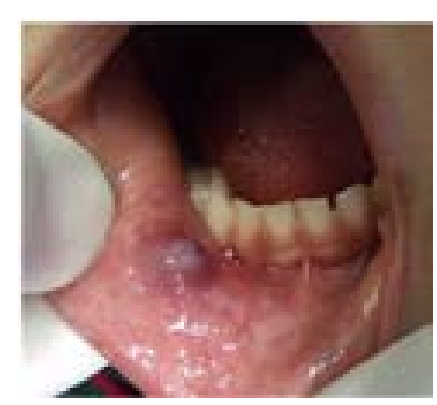

Figure 1: Clinical view of the lesion before treatment

A gradual increase in size with some episodes of emptying and recurrence was noticed by the parents. Also, the patient's mother reported a lip biting habit in her offspring. The swelling was painless, and no history of fever or malaise was reported. The medical and familial history of the patient was unremarkable.

The extraoral examination was normal, whereas the intraoral examination revealed a sessile, nodular and exophytic lesion on the lower lip. The lesion was blue in color with a fluctuant consistency.

Diagnosis of a mucocele was made based on the clinical view and the history of lip biting. Because of the invasiveness of the surgical treatment as well as the patient's questionable cooperation, the authors decided to manage the lesion with a more conservative treatment using corticosteroid injections. Written informed consent was received from the patient's parents.

Two consecutive intralesional injections of 40 $\mathrm{mg} / \mathrm{ml}$ triamcinolone acetonide (Alborz Darou, Iran) were done at the base of the lesion under inferior alveolar nerve anesthesia. Based on the clinician's experiences, $1 \mathrm{ml}$ of the drug was injected during the first injection. After one week, the next injection was performed by the use of $0.5 \mathrm{ml}$ of the drug. A significant reduction in size $(1.5 \times 1.5 \mathrm{~cm}$ versus $0.4 \times 0.4 \mathrm{~cm})$ was observed after the first injection, and the lesion completely disappeared after two weeks (Figure 2). The patient was followed for one year, and fortunately, no recurrence was reported. 


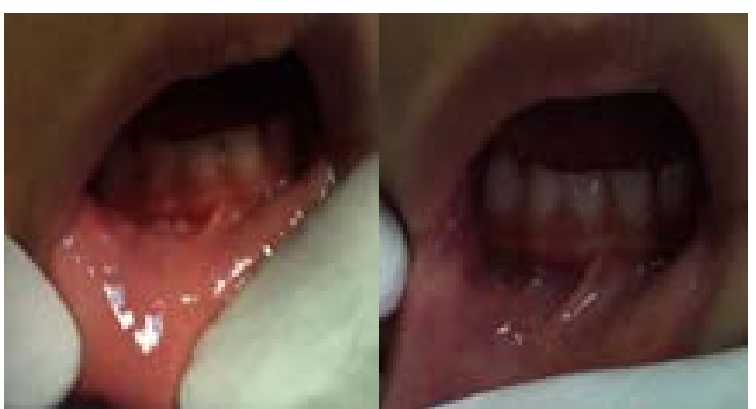

Figure 2: (A) Clinical view of the lesion after one week. (B) Clinical view of the lesion after two weeks

\section{Discussion:}

Mucocele is a common self-limiting nonneoplastic lesion. ${ }^{(1,5)}$ It is highly prevalent with 2.5 cases per 1000 individuals. ${ }^{(7)}$ Frequent episodes of rupture may happen, and the retention of the saliva may redevelop, resulting in the recurrence of the lesion. ${ }^{(8)}$ Although this lesion may occur on any surface containing minor salivary glands, the lower lip is more frequently involved.( ${ }^{(3)}$ Ranula is a type of mucocele, which appears on the floor of the mouth and is related to a major salivary gland i.e. the sublingual gland..$^{(4)}$ Ranula originating from the submandibular gland is rare. Choi et al reported bilateral mucoceles related to the submandibular salivary gland. ${ }^{(9)}$

As described in the current case report, the patient had a history of lip biting, causing constant minor trauma to the same site. Therefore, the mucocele recurred repeatedly. In order to prevent the recurrence of the lesion, the habit had to be stopped. The parents and the child were informed, and a reward system was used for habit cessation. Fortunately, after about one month, the habit was stopped completely.

Although mucoceles are often painless and do not cause patient discomfort, sometimes, they may interfere with normal oral functions such as speech, chewing, or swallowing; ${ }^{(10)}$ in these cases, removal of the lesion is essential. Various types of treatment options have been described previously. The conventional treatment is surgical excision. In this technique, the whole lesion and the related salivary gland are removed. However, since surgery may damage the adjacent minor salivary glands, development of a new mucocele is probable. ${ }^{(1)}$
Also, as surgery is a potentially invasive procedure, it may produce psychological and behavioral problems in pediatric patients; therefore, some additional aids such as sedation or general anesthesia may be required. ${ }^{(11)}$ Another alternative treatment modality is cryosurgery, which is based on the rapid freezing of the lesion using liquid nitrogen. ${ }^{(5)}$ It has been demonstrated that only two (5.6\%) recurrences were observed among 36 mucoceles treated by cryosurgery. ${ }^{(5)}$ There are some disadvantages related to this technique, such as post-operative edema, irritation, and prolonged healing time. (5) In larger mucoceles, marsupialization may be performed. The purpose of this technique is to reduce the size of the lesion. Although this method is simple and noninvasive to vital adjacent structures, recurrence may occur. ${ }^{(7)}$

Different types of lasers have been used for removal of mucocele with satisfactory results. Lasers create a perfect cut with minimum patient discomfort and minimal hemorrhage. ${ }^{(10)}$ Also, the operation time is short with lasers and tolerable by younger patients. ${ }^{(7,10)}$ However, the required equipment is expensive and not available at every facility.

Behavioral management is essential in pediatric patients. A child with an oral pathology is anxious and susceptible to behavior problems. Practitioners who work with children have to take this point into consideration and use less invasive treatment procedures as possible. Intralesional corticosteroid injections are considered a less invasive treatment option. ${ }^{(1)}$

The result of our study suggests corticosteroids as effective medications in the treatment of recurrent mucoceles; this finding is in agreement with the results reported by Luiz et al after the application of topical corticosteroids. ${ }^{(6)}$ In the present case, the lesion completely disappeared after two consecutive intralesional injections of triamcinolone acetonide, and no recurrence was reported within the one-year follow-up.

Intralesional steroids have some advantages over the topical ones, including the bypass of the oral mucosal barrier, reducing the chance of mucosal atrophy, and delivery of higher concentrations of drug to the site of the lesion. ${ }^{(12)}$ 
The only disadvantage is that intralesional injection is more invasive compared to the topical application of steroids. ${ }^{(6)}$

The efficacy of corticotherapy is likely attributable to the high-potency vasoconstriction and antiinflammatory properties of this product, reducing the inflammatory process involved in the pathogenesis of mucoceles. ${ }^{(13)}$

Mortazavi et al considered a combination of intralesional dexamethasone and micro-marsupialization for the treatment of a mucocele on the lower lip. ${ }^{(13)}$ The present case report revealed that in smaller lesions, intralesional injection alone may lead to the complete resolution of the lesion with no future recurrences.

\section{Conclusion:}

The results of this case report suggest that intralesional corticosteroid injection may be considered a less invasive and cost-effective approach for the management of oral mucoceles, especially when surgical intervention is precluded.

\section{Acknowledgement:}

We are thankful to those who helped us in this article including research center of Islamic Azad university - Dental Branch.

\section{References:}

1. Sinha R, Sarkar S, Khaitan T, Kabiraj A, Maji A. Nonsurgical Management of Oral Mucocele by Intralesional Corticosteroid Therapy. Int J Dent. 2016;2016:2896748.

2. Nallasivam KU, Sudha BR. Oral mucocele: Review of literature and a case report. J Pharm Bioallied Sci. 2015 Aug;7(Suppl 2):S731-3.

3. Anastassov GE, Haiavy J, Solodnik P, Lee H, Lumerman H. Submandibular gland mucocele: diagnosis and management. Oral Surg Oral Med Oral Pathol Oral Radiol Endod. 2000 Feb;89(2):159-63.

4. Baurmash HD. Mucoceles and ranulas. J Oral Maxillofac Surg. 2003 Mar;61(3):369-78. 5. Yeh CJ. Simple cryosurgical treatment for oral lesions. Int J Oral Maxillofac Surg. 2000 Jun;29(3):212-16.

6. Luiz AC, Hiraki KR, Lemos CA Jr, Hirota
SK, Migliari DA. Treatment of painful and recurrent oral mucoceles with a high-potency topical corticosteroid: a case report. J Oral Maxillofac Surg. 2008 Aug;66(8):1737-9.

7. Ata-Ali J, Carrillo C, Bonet C, Balaguer $\mathrm{J}$, Peñarrocha M. Oral mucocele: Review of the literature. J Clin Exp Dent. 2010 Feb;2(1):e18-21.

8. Boneu-Bonet F, Vidal-Homs E, Maizcurrana-Tornil A, González-Lagunas J. Submaxillary gland mucocele: presentation of a case. Med Oral Patol Oral Cir Bucal. 2005 Mar-Apr;10(2):180-4.

9. Choi HJ, Kim SG, Kim JD, Kim JH, Kim JH, Kim SM. A case of bilateral submandibular gland mucoceles in a 16-month-old child. Korean J Pediatr. 2012 Jun;55(6):215-8.

10. Chawla K, Lamba AK, Faraz F, Tandon S, Arora S, Gupta M. Treatment of lower lip mucocele with Er,Cr:YSGG laser - a case report. J Oral Laser Applications. 2010 Winter;10(4):181-5.

11. Nico MM, Park JH, Lourenço SV. Mucocele in Pediatric Patients: Mucocele in pediatric patients: analysis of 36 children. Pediatr Dermatol. 2008 May-Jun;25(3):308-11.

12. Sastre J, Mosges R. Local and systemic safety of intranasal corticosteroids. J Investig Allergol Clin Immunol. 2012;22(1):1-12.

13. Mortazavi $\mathrm{H}$, Baharvand $\mathrm{M}$, Alirezaei S, Noor-Mohammadi R. Combination therapy in a large lower lip mucocele: A non-invasive recommended technique. Dent Hypotheses. 2014;5(3):127-9. 